\title{
The Teaching Reform of Practical Training for Agricultural Mechanization and Automation Engineering under the Background of Robot Substitutions
}

\author{
Song xin \\ College of Engineering and Technology \\ Tianjin Agricultural University \\ Tianjin, China \\ songxin-tju@163.com \\ Li Yancong \\ College of Engineering and Technology \\ Tianjin Agricultural University \\ Tianjin, China \\ lyc65@163.com
}

\author{
Shi Yu \\ College of Engineering and Technology \\ Tianjin Agricultural University \\ Tianjin, China \\ syych83@tjau.edu.cn \\ Shan Huiyong \\ College of Engineering and Technology \\ Tianjin Agricultural University \\ Tianjin, China \\ tjshy@sohu.com
}

\begin{abstract}
In order to meet the demands of talents cultivation and adapted to the industrial development under the background of robot substitutions, the teaching reform of practical training for agricultural mechanization and automation engineering based on the theory of CDIO is proposed, according to the requirements of Chinese traditional agriculture transfer to modern agriculture and the inevitable trend of the intelligent agricultural machinery and equipment development. The practice shows that the teaching mode of teaching, learning and doing integration, and learning, training and match connection can expand students' learning space, and their professional skill, innovative and social ability is trained and upgraded in all directions. Also a stable and effective training platform for the agricultural robot professional skill personnel is provided.
\end{abstract}

Keywords—robot substitutions; agricultural mechanization and automation; CDIO; teaching reform of practical training

\section{INTRODUCTION}

Based on the modernization and automation equipment, the robot substitutions are used to upgrade traditional industries, by using manipulator, automation control equipment or assembly line automation for the intelligent technological transformation to the enterprises, to achieve the purpose of "downsize staffs, improve efficiency and quality, ensure the safety." The new concept is gradually proposed in the eastern China in recent years and is accepted by the majority of the traditional manufacturing industry. There are two backgrounds for the appearance of the new concept. One is that the disappearing demographic dividend, growing labor shortage and rising labor costs compresses the living space of the traditional production mode. The other one is that Chinese economy is in the transformation and upgrading of the structure adjustment under the government leading, and the enterprises must keep up with

The research was sponsored by the undergraduate education and teaching research and reform project of Tianjin Agriculture University (2014-B-09) and the teaching reform project of experimental teaching demonstration center in Tianjin Agriculture University (2015SY023, 2015SY018).. the Chinese economy by the pace of made in China transfer to create in China, both in the software and hardware. By the robot substitutions, the improvement for the production efficiency and stability of the quality and then the contribution to enhance the benefit of enterprises is better than the accumulation advantages of technology, talent and capital during a certain period of time. The laws of economic development and technique progress which lead to the inevitable trend have decided that the robot substitutions is the inevitable choice to promote technological dividend instead of demographic dividend, and for Chinese manufacturing industry optimization upgrading and sustainable economic growth.

On the one hand, China is a large agricultural country, the agricultural population is numerous and the proportion of the total population is about $43.9 \%$ [1]. While the accelerating process of Chinese industrialization, agricultural labor force is gradually transfer to other industries, and meanwhile China is also facing the problem of population aging which is much worse than any other countries in the world. The problem of shortage of agricultural labor has been increasingly revealed. Coupled with labor intensive and the working characteristics of farming constrained by season, in China, it is necessary to accelerate the transformation from traditional agriculture to modern agriculture, increase the application of the intelligent agricultural machinery and equipment, including the promotion and application of agricultural robot, to solve the reality problem due to the shortage of rural labor force.

On the other hand, China has become the world's largest manufacturing and usage of agricultural machinery currently. The transformation of modern agriculture has brought the great opportunity for intelligent agricultural machinery and equipment. Agricultural production is moving towards the direction of new four modernizations that is the agricultural 
information technology, precision planting, operation automation and intelligent control. For the first time, China Manufacturing 2025 sets the agricultural machinery industry equipment to the ten important development areas, aimed at the high-end agricultural equipment and promoting the deeply integration of digital, intelligent and agricultural equipment[2]. Meanwhile, the subsidy for agricultural innovation, and the generalized system of preferences for the agricultural machinery both support high-end innovative products in 2015. Furthermore, the process for subsidy of purchase is simplified in One Step, providing the policy support for the promotion of intelligent agricultural equipment. The agricultural robot has become the strategic requirements in the new period for the country, the requirements of the transformation of agricultural machinery and the industrial requirements of the market. As Chinese agriculture has entered a turning point, the business scale, the capital of investment, the automation of agricultural machinery and the professionalization of farmers will make agricultural planting and breeding industry vigorously promote agricultural robots.

In summary, from the perspective of the current agricultural development, on the one hand, the implementation of agricultural robot substitutions will be the inevitable trend in the future of Chinese agricultural development. The Chinese agriculture will face robot time as same as the industry. The requirements of the agricultural robot market will increase rapidly. On the other hand, the related technical talents for the agricultural robot research, development and usage cannot follow up persistently, which has resulted in a large shortage of professional talent and directly restricting the development of Chinese agricultural robot industry. Therefore, the university which is specialized in training talents for agricultural mechanization and automation professional application must positive think and explore the new mode of training agricultural robot talent for the development of local agricultural robot substitutions industry.

\section{THE REQUIREMENTS AND CURRENT SITUATION OF THE TALENT TRAINING UNDER THE BACKGROUND OF AgRICULTURAL ROBOT SUBSTITUTIONS}

On the basis of the traditional agricultural machinery and equipment, the agricultural robot make the agricultural equipment realize the function of automation, intelligence, information technology and human machine separation under the unstructured environment by the fusion of biological and agronomic techniques, as well as the high technology integration such as the sensor, automatic control, mechanical electrical and hydraulic, information processing and artificial intelligence, increasing the function of intelligent control and artificial intelligent decision,. The complexity and multiknowledge crossed are the characteristics of the key technology and professional knowledge for the agricultural robot. To research and develop the application of the agricultural robot, it is necessary to have the comprehensive professional and technical team, which knows the machinery, electronics, control, and computer and information technology, understands the biological and agronomic techniques and can manipulate, manage and maintenance the intelligent agricultural machinery and equipment. And it is the key point for implement of the robot substitutions in agricultural field.

But, at present in our teaching system, the theory teaching is set as the main body, by inculcation education. The verification of practice teaching mode is often used in many important experiments and practice teaching links, the students lack the opportunities for hands-on practice. So it is difficult for students to establish a valid relationship between theoretical knowledge and practical. In addition, the teaching contents and curriculum design updates slowly and relatively lags, and seriously disconnects the development process of the modern agricultural intelligent equipment technology. As a result, the training skilled talents are mostly semi-finished products, which cannot meet the actual requirements of the job skill [3].

Therefore, as the university which is specialized in training talents for agricultural professional application, it should actively explore the teaching reform of practical training to meet the requirements of the development of Chinese agricultural robot industry. So that the applied technical talents, which not only have system knowledge in the structure and controlling of agricultural machinery and equipment, but also can combine the agronomic with the biological characteristics of agricultural object to propose the plan for automation solution and organize the implementation, is trained for the region and even for the country in the agricultural field. And it provides the reserve talents guarantee to support the achievement of independent research and development and widely application for the agricultural robot in China.

\section{TEACHING REFORM OF PRACTICAL TRAINING IN Agricultural MECHANIZATION AND AUTOMATION BASED ON CDIO}

The ideas of CDIO engineering education are proposed by a multinational research group. The research group is headed by Professor Ed. Crauley, which is the NAE member, and established by the Massachusetts Institute of Technology and the Royal Institute of technology in Sweden and other four universities[4]. CDIO is an education method oriented to students, which emphasizes in the process of conceive, design, implementation and operate the real world system and product, to learn the theory and practice of engineering. It is the centralized reflection of "learning through doing" and "education and learning based on the project", which inherits and develops the engineering education reform philosophy in Europe and the United States over the past twenty years [5]. Also it is the latest achievements of international engineering education reform, and is a kind of innovation for engineering education mode in recent years.

Combined with the actual situation of our college teaching, the new practical training mode that teaching, learning and doing integration, and learning, training and match connection is proposed based on the basic concept and theory of CDIO.

\section{A. Teaching, Learning and Doing Integration}

The former premier Wen Jiabao has stressed: "Learning through doing is the true learning, and teaching through doing is the true teaching." [6] The core idea of the teaching, learning and doing integration is the theoretical practice integration 
teaching method. The method integrates the theory and practice teaching of the agricultural mechanics, mechanical principles, mechanical design, electronic circuit, fundamentals of MonoChip Computers and control theory and some other professional courses, breaking the boundaries of the original theory, experiment and practical training courses. By using the project teaching method, the students complete the whole process of the practical project which sets the agricultural robot research and development as practical training content, based on the requirements of the agricultural machinery manufacturing enterprises or agriculture. Therefore, the synchronization of theoretical study and practice is realized and the learning process of the students is closer to the situation of the practical work in the future.

The teaching mode of integration of the teaching, learning and doing has changed the slight and split practice link in the former teaching mode that theory is first and practice is second. And the training process is no longer a passive process of the teacher unilateral imparting knowledge to students. It is an active process for the students' affinity. By active learning, self-discovery, self-evaluation and self-creation, the meaningful and valuable of professional skill, the method and experience is abstracted from the concrete object of engineering practice. Moreover, in the created real situation, the students can be trained to make plan and decision, participate in the discussion and learn the method to solve the problem. Essentially, the students are trained to analyze problem, solve problem and make a reasonable decision by thinking, which lays the foundation for future employment, adapting to the workplace and society.

On the other hand, the good scientific attitude, scientific spirit and scientific thinking are cultivated for students during the full experience of the scientific exploration process. The target of the practical training is not merely to let the students learn something, and the more important thing is to know how to deal with. So that the lifelong learning ability is formed and the condition is created for training the high quality innovative talents of high-level, compound type and diversity.

\section{B. Learning, Training and Match Connection}

With the coming robot time in China, as well as the continuous renewal of educational ideas, there have been a series of domestic robot match in recent years, for training and selecting the excellent talents of robot technology. Hence, the teaching links of engineering practical training is created as the centralized training platform for students to participate in various types of robot skill match, which relies on the robot professional match by our specialty. The training for robot development is used to provide the reservation of the knowledge, technology and experience for participating in the match at the process of theoretical study and practice. Meanwhile, participating robot match is also an extension of the content of the comprehensive training courses, an exhibition and inspection of the practical training.

The Robotic Innovation Laboratory provides sufficient software and hardware for students to carry out agricultural robot technology innovation project and participate in various types of robot match. The ability which is all required in engineering work, including professional and technical knowledge, practice, personal and professional ability and attitude, team work and communication skill, can be exercised and enhanced in the implementation of engineering practical training. Meanwhile, all that is the necessary personal quality which is required in the professional skill match. Due to many robot enterprises intend to organize and attend the robot match, the excellent talents and enterprises can communicate directly. On the one hand, the students will understand the actual requirements for the enterprises and definite their employment direction and development goals. On the other hand, the robot enterprises can realize the professional level of the students and provide a good employment channel for the students who own innovative thinking and ability.

\section{CONCLUSIONS}

Based on the robot substitutions, the teaching reform of practical training in agricultural mechanization and automation has been implemented to four grades and eight classes for three years. Through the combination of theoretical knowledge, project training and the actual missions, the students' learning space is expanded and their professional skill, innovative and social ability are trained and upgraded in all directions. The agricultural picking robot, intelligent weeding robot and intelligent monitoring system for farm which is self-researched by students have wined the first prize three times, the second prize nine times and the third prize seven times in China Robot Match, the Five Provinces of Northern China University Robot Match, Tianjin Challenge Cup. Besides, five papers have been published and three items of national utility model patent have been authorized.

The teaching reform of engineering practical training in our college is a beneficial attempt to train the excellent technology talents in agricultural robot, who own solid professional knowledge, strong practical and innovation ability. And it provides personnel support to the transformation and development of modern agricultural machinery and equipment industry.

\section{ACKNOWLEDGMENT}

In this paper, the research was sponsored by the undergraduate education and teaching research and reform project of Tianjin Agriculture University (2014-B-09) and the teaching reform project of experimental teaching demonstration center in Tianjin Agriculture University (2015SY023, 2015SY018).

\section{REFERENCES}

[1] National Bureau of Statistics. The statistical bulletin of the national economic and social development in 2015 [EB/OL]. http://www.stats.gov.cn/tjsj/zxfb/201602/t20160229_1323991.html, 2016-02-29(In Chinese).

[2] Chinese State Council. China Manufacturing 2025 [EB/OL]. http://www.gov.cn/zhengce/content/2015-05/19/content_9784. htm,2015-05-08/2015-05-19] (In Chinese).

[3] Du Liuqing, Yu Yongwei, Zhou Kangqu, Mi Lin. Research on the teaching reform of mechanical engineering core curriculum with the aim 
of training students' engineering design ability [J]. Education Teaching Forum,2014,9(36):42-44(In Chinese).

[4] Gu Peihua, Bao Nengsheng, Kang Quanli, Lu Xiaohua etc. CDIO in China [J]. Research in Higher Education of Engineering,2012(3):2440(In Chinese).

[5] Gu Peihua, Shen Minfeng, Lu Xiaohua. Re-recognition of engineering education-the international CDIO training mode and method [M].Beijing:Higher Education Press,2009(In Chinese).
[6] Zha Jianzhong. Strategy of engineering education reform in the era of economic globalization-industry-academy cooperation and internationalization [J]. Research in Higher Education of Engineering,2008(1):21-27(In Chinese). 